Article

\title{
Evaluation of Water Resources Security in the Karst Region from the "Man-Land-Water" Perspective: A Case Study of Guizhou Province
}

\author{
Qun-Wei Zheng ${ }^{1}{ }^{\mathbb{D}}$, Wei-Ci Su ${ }^{1,2, *}$, Feng-Tai Zhang ${ }^{3, *}$ and Zi-Qin Zhou ${ }^{1}$ \\ 1 Geography and tourism college, Chongqing Normal University, Chongqing 400047, China; \\ zhengqw158@163.com (Q.-W.Z.); cszhou_zq@163.com (Z.-Q.Z.) \\ 2 Institute of mountain resources of Guizhou Academy of Sciences, Guiyang 550001, Guizhou Province, China \\ 3 School of Management, Chongqing University of Technology, Chongqing 400054, China \\ * Correspondence: suweici@sina.com (W.-C.S.); zhfthero45@cqut.edu.cn (F.-T.Z.)
}

Received: 25 November 2018; Accepted: 23 January 2019; Published: 29 January 2019

\begin{abstract}
This paper constructs a water resources security evaluation model from the "man (human activity intensity)-land (geological and geomorphological features)-water (water resources background conditions)" perspective, which accounts for the characteristics of hydrology and water resources in karst areas. A water resources security evaluation index system is established from three aspects (i.e., the background conditions of water resources, human activity intensity and geological and geomorphological features). The evaluation standard threshold is determined in accordance with relevant standards and domestic/foreign development experience. Both the comprehensive weights obtained by the Lagrange coefficient and the multi-objective fuzzy membership functions are used to comprehensively evaluate the spatial and temporal evolution of water resources security in Guizhou Province from 2001 to 2015. The results show that the water resources security comprehensive index of Guizhou Province was between 0.6 and 0.8 during this time (relatively safe type) and the safety was trending upwards. However, the comprehensive index of water resources security of each city in Guizhou Province demonstrates significant spatiotemporal variation. Whilst the comprehensive index was low in the Western part and high in the Eastern part of the province, it generally improved over time for the entire province. Moreover, the criteria layer indexes of water resources security in Guizhou Province and all cities also showed different degrees of variation and regional consistency across space and time. The interaction among these three aspects promoted the spatiotemporal variation of the Water Resources Security Comprehensive Index. In order to safeguard and improve water resources security, it is important to strengthen ecological and environmental management, promote the efficient use of water resources, establish sound management measures and security system related institutions and ensure water resources security.
\end{abstract}

Keywords: karst region; water resources security; the "man-land-water" concept model; multi-objective fuzzy membership function; time and space evolution

\section{Introduction}

Water resources serve an important role in promoting stable development of the social economy and supporting the ecological environment of a region and country [1,2]. Increasing water shortages in many regions are becoming important water security challenges in the field of hydrology and water science. Therefore, many in-depth studies have been carried out on the influencing factors, evaluation systems, safety mechanisms, guarantee and early warnings of water resources [3-8]. Among these studies, water resources security (WRS) evaluation is one of the key issues in WRS research. The core 
of WRS evaluation is to select and determine reasonable water security metrics, thereby constructing a comprehensive measurement model for water security assessment.

Recent studies have investigated a range of evaluation metrics and evaluation methods in relation to WRS. These studies cover the definition of WRS $[9,10]$, the construction of an evaluation index system [11,12] and the design and selection of evaluation models [13]. A review of the literature showed, some commonly used evaluation indicators including the water safety index, water shortage index, water pressure comprehensive index, water poverty index and water resources carrying capacity index [14-19]. Modelling methods include the set pair analysis method, the comprehensive index method, the matter element model method, the system dynamics model, the artificial neural network model, the projection pursuit model and the logical logic curve model [20-25].

For instance, Gong [26] defined WRS as the ratio of water demand to water supply; and Gong also classified five graded levels (i.e., safe, relatively safe, critically safe, unsafe and extremely unsafe). Based on the relationship between humans and water, Bao [3] constructed an evaluation index system to evaluate the WRS pattern of the Beijing-Tianjin-Hebei urban agglomeration. In karst areas, Zhang [27] applied the DPSIRM (driving force-pressure-state-impact-response-management) model to develop a corresponding evaluation index system and they comprehensively evaluated the WRS conditions of Guizhou Province. By using a conceptual model called PESBR (pressure-engineering water shortage-water bearing state-ecological basis-anthropogenic response), Yang [28] established an evaluation index system that considers the engineering water shortage characteristics of karst areas and performed a dynamic evaluation of WRS in Guiyang. Wang [29] adopted the ecological footprint theory to analyse the development and utilization of regional water resources. Hence, these studies promoted the development of this theory. There are some shortcomings: (1) The choice of indicators has merely focused on the relationship between humans and water, while ignoring the role of natural conditions (such as geological features) on WRS; (2) the determination of the weight of the indicator has primarily depended on expert judgement with strong subjectivity, hence ignoring the objective aspect of the indicator.

Karst areas are "two-phase three-dimensional" spatial structure system composed of double water-bearing media. Their special geomorphological-hydrological structure could cause quantity and quality issues in WRS. In addition, it could also lead to rapid surface water conversion, soil erosion (leakage), complex groundwater storage conditions, difficulty in water intake and difficulties in acquiring drinking water for people and livestock scattered throughout rural areas and so forth. To a certain extent, the challenges of water resource security in karst areas are typically characterized by special topographical conditions, poverty and shortage of surface water resources. Based on these criteria, this study constructs a comprehensive evaluation index system of water resources from the three-dimensional perspective of "human (economic and social activities taken by humans)-land (geological and geomorphological environment)—water (water resources endowment)." This paper uses a combined weight method to determine the weight of each index and develop a WRS evaluation model for Guizhou Province. From there, we perform a comprehensive evaluation on the spatial-temporal pattern of WRS, covering many cities within Guizhou Province. The outcomes of this study provide a scientific basis for the sustainable development and protection of water resources in Guizhou province.

\section{Water Resource Safety Evaluation Model}

\subsection{Evaluation Index System Based on the "Man-Land-Water" Concept}

The water resources system is a massive complex system because WRS can be affected by many factors. At the top factor is human activities, while WRS in karst areas is also shaped by their special geological/geomorphological characteristics and the occurrence of water resources conditions.

(1) The "man-land-water" conceptual model 
The man-land-water combination constitutes a natural-social water resources dual-cycle structure system (Figure 1). Based on this concept, the WRS utilization process is affected by many factors. The meteorological, hydrological and geological features can determine the original spatial distribution of surface water resources. Human activities such as new reservoirs and groundwater pumping can modify the original configuration characteristics of surface water and groundwater resources.

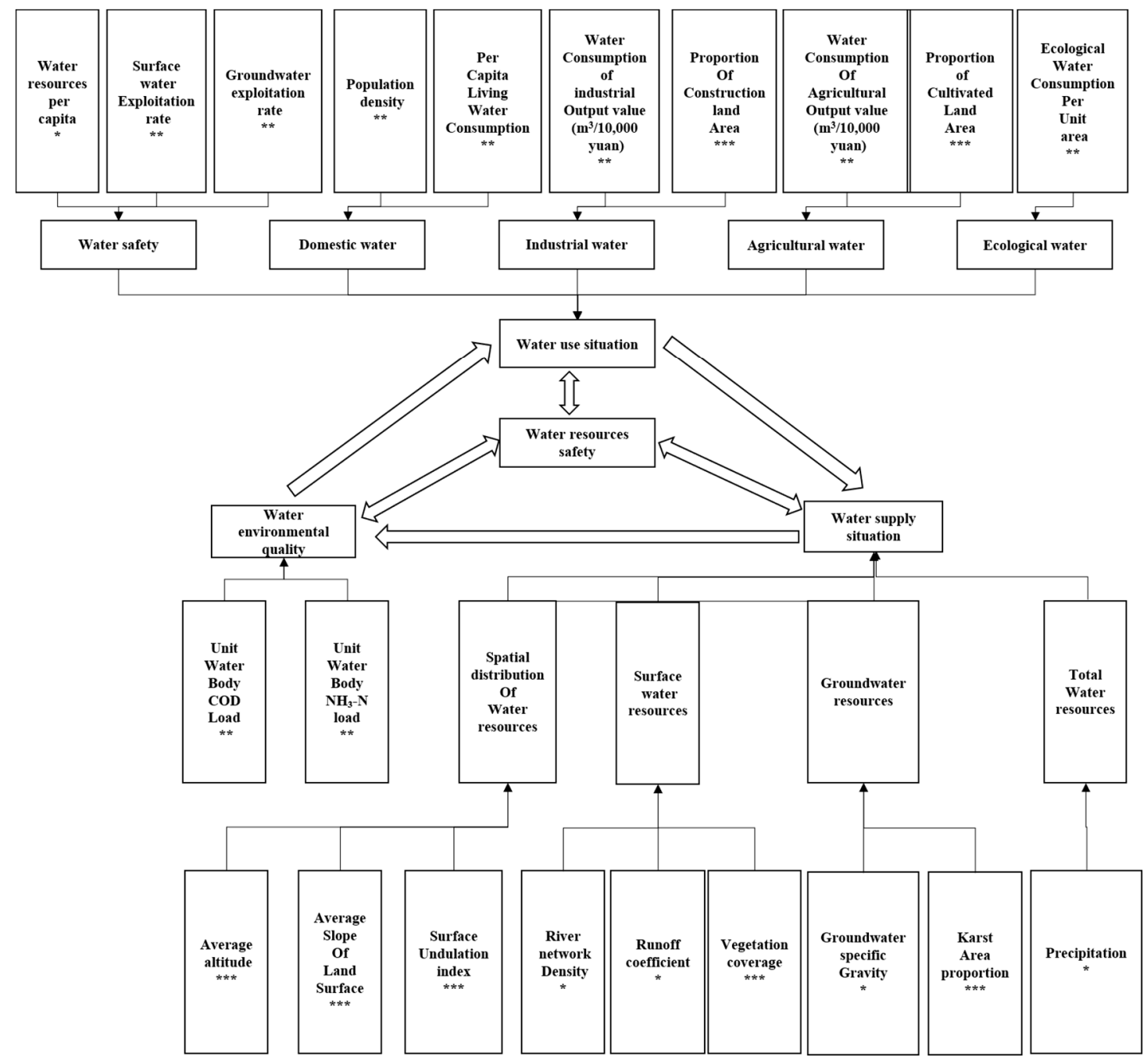

Figure 1. Water resources security "man-land-water" conceptual model framework. * Represents water resources background conditions. ${ }^{* *}$ Represents human activity intensity. ${ }^{* * *}$ Represents geological and geomorphological features. The arrows indicate the direction of influence.

From the perspective of a man-water relationship, water demand driven by human activities would gradually increase. With increasing development of the social economy, residents' living standard requirements and population growth concentrated in karst areas will result in an increase in municipal and industrial water consumption. The adjustment of agricultural structures could also lead to an increase in agricultural water consumption in this region. When the spatial distribution of water resources is uneven, droughts and floods might occur on a seasonal basis. For example, Bijie City has always been adversely affected by water shortages, while some parts of Southwestern Guizhou are frequently troubled by urban flooding problems. Moreover, an increase in water consumption is generally accompanied by an increase in sewage discharge, which, in turn, cause water pollution. This is especially the case in areas with abundant precipitation and severe surface water leakage, which poses hidden threats to groundwater quality. 
From the perspective of a man-land relationship, the topography and geomorphology of a landscape (e.g., large surface undulations and high mountains and steep slopes) are difficult to change. Rapid urbanization processes are driving the expansion of construction lands in urban and rural areas; intensive farming in croplands is reducing the ability of the croplands to store water and solidify soil, causing soil erosion and rocky desertification. In addition, the moderate-strength rocky desertification area lacks the ability to retain surface water resources, which in turn reduces the residents' production water and domestic water.

\section{(2) Construction of an index system}

Following the principles of combining science with comparability, systematicity and hierarchy, comprehensiveness, dominance, pertinence and feasibility, and referring to the related literature of WRS in karst areas [2,3,11,13,20-29], we form a hypothesis regarding the basis of the active role and adaptability of human beings in relation to the utilization of water resources. The influences of geology and geomorphology on the background of water resources and the guaranteed effects of water resources on human life, production and ecological needs, according to the connotations of the concept model of "man-land-water," led us to select 21 indicators to construct a comprehensive evaluation index system for WRS in Guizhou Province (Table 1). Based on the attributes of these indicators, they were divided into negative and positive tropism indicators. The weights of these indicators were also evaluated.

Table 1. Guizhou Province water resources security evaluation index system.

\begin{tabular}{|c|c|c|c|c|}
\hline Target Layer & $\begin{array}{l}\text { Criteria Layer } \\
\text { (Weight) }\end{array}$ & $\begin{array}{l}\text { Indicator } \\
\text { Attribute }\end{array}$ & Indicator Layer (Unit) & Weight \\
\hline \multirow{21}{*}{$\begin{array}{l}\text { Water resources } \\
\text { security }\end{array}$} & & $X_{1}+$ & Precipitation $(\mathrm{mm})$ & 0.0428 \\
\hline & Water resource & $X_{2}-$ & The proportion of groundwater (\%) & 0.0495 \\
\hline & background & $X_{3}+$ & Runoff coefficient & 0.0596 \\
\hline & $(0.2556)$ & $X_{4}+$ & River network density $\left(\mathrm{km} / \mathrm{km}^{2}\right)$ & 0.0652 \\
\hline & & $X_{5}+$ & Water resources per capita $\left(\mathrm{p} / \mathrm{m}^{3}\right)$ & 0.0385 \\
\hline & \multirow{9}{*}{$\begin{array}{l}\text { Human activity } \\
\text { intensity }(0.4003)\end{array}$} & $X_{6}-$ & Surface water exploitation rate (\%) & 0.0424 \\
\hline & & $X_{7}-$ & Groundwater exploitation rate (\%) & 0.0631 \\
\hline & & $X_{8}-$ & Population density $\left(\mathrm{p} / \mathrm{km}^{2}\right)$ & 0.0485 \\
\hline & & $X_{9}-$ & $\begin{array}{l}\text { Water consumption of industrial output value } \\
\qquad\left(\mathrm{m}^{3} / 10,000 \text { yuan }\right)\end{array}$ & 0.0588 \\
\hline & & $X_{10^{-}}$ & $\begin{array}{l}\text { Water consumption of agricultural output value } \\
\qquad\left(\mathrm{m}^{3} / 10,000 \text { yuan }\right)\end{array}$ & 0.0287 \\
\hline & & $X_{11-}$ & Domestic water consumption per capita $\left(\mathrm{m}^{3} / \mathrm{p}\right)$ & 0.0459 \\
\hline & & $X_{12}+$ & Ecological water consumption per unit area $\left(\mathrm{m}^{3} / \mathrm{km}^{2}\right)$ & 0.0214 \\
\hline & & $X_{13}-$ & $\begin{array}{c}\text { Unit water body Chemical Oxygen Demand(COD) } \\
\text { load (mg/L) }\end{array}$ & 0.0416 \\
\hline & & $X_{14}-$ & Unit water body $\mathrm{NH}_{3}-\mathrm{N}$ load $(\mathrm{mg} / \mathrm{L})$ & 0.0498 \\
\hline & \multirow{7}{*}{$\begin{array}{l}\text { Geological and } \\
\text { geomorphological } \\
\text { features }(0.3439)\end{array}$} & $X_{15}-$ & Average slope of land surface & 0.0449 \\
\hline & & $X_{16}-$ & Surface undulation index & 0.0550 \\
\hline & & $X_{17}-$ & Karst area proportion (\%) & 0.0635 \\
\hline & & $X_{18}-$ & Average altitude & 0.0390 \\
\hline & & $X_{19+}$ & Vegetation coverage $(\%)$ & 0.0595 \\
\hline & & $X_{20-}$ & Proportion of cultivated land area (\%) & 0.0502 \\
\hline & & $X_{21}-$ & Proportion of construction land area (\%) & 0.0318 \\
\hline
\end{tabular}

\subsection{Methods}

\section{(1) Determine indicator weight}

Traditional methods for determining weights are affected by both subjective and objective factors $[13,30]$. To account for the subjective factors and objective information in setting the weights, we used the AHP (Analytic Hierarchy Process) to determine the subjective weight $W_{1 j}$, we adopt the entropy weight method to determine the objective weight $W_{2 j}$ and we applied the Lagrange multiplier method to obtain the comprehensive weight $W_{j}$ (Table 1). We note that some indicators (such as the 
mean slope, altitude, surface undulation and runoff density) do not change much over many years. When the entropy weight method was used to calculate the weight of each index, these indicators were first removed. We calculated the $d_{j}$ of the remaining indicators using Equation (3) and assigned the average value of $d_{j}$ to each elimination indicator for the calculation of the $W_{2 j}$. The AHP decomposed the complex problems into several levels. Then, the decision makers and experts constructed the judgment matrix through comparing their levels of importance with the indicators at the same level and the eigenvectors of the judgment matrix were used to determine the contribution of the index to its upper-level indicators. From there, the weighted results of the grassroots indicators to the overall goal were obtained [30]. Based on the degree of variation of each index and the principle of information entropy, we applied the entropy weight method to calculate the entropy weight of each index [13]. The calculation process sued was as follows:

We set the value of the $j$-th influence factor in the subsystem of the $i$-th period as $X_{i j}(i=1,2, \ldots, n$; $j=1,2, \ldots, \mathrm{m})$ and performed non-negative processing on each indicator:

$$
X_{i j}=\frac{X_{i j}-\min \left(X_{i j}\right)}{\max \left(X_{i j}\right)-\min \left(X_{i j}\right)}+1
$$

We calculate the proportion of the factor sum in all time periods that the $j$-th influence factor of the $i$-th period accounts for using:

$$
P_{i j}=\frac{X_{i j}}{\sum_{i=1}^{n} X_{i j}}(i=1,2, \ldots, \mathrm{n} ; j=1,2, \ldots, \mathrm{m})
$$

The weights of the indicators in the subsystem were calculated as [13]:

$$
W_{2 j}=\frac{d_{j}}{\sum_{j=1}^{m} d_{j}}(1 \leq j \leq m)
$$

In the following equation: $d_{j}=\frac{1-e_{j}}{m-\sum_{j=1}^{m} e_{j}}\left(0 \leq d_{j} \leq 1, \sum_{j=1}^{m} d_{j}=1\right) ; e_{j}=-\frac{1}{\ln (n)} \times \sum_{i=1}^{n} P_{i j} \ln \left(P_{i j}\right)$.

Finally, the Lagrange multiplier method was applied to obtain the optimal solution, that is, the comprehensive weight:

$$
W_{j}=\sqrt{W_{1 j} W_{2 j}} / \sum_{j=1}^{n} \sqrt{W_{1 j} W_{2 j}}
$$

(2) Grade hierarchical criteria

In order to make the evaluation results comparable on both temporal and spatial scales at high levels of statistical significance, we referred to research literature of water security at home and abroad, combined with the WRS index critical value and the related domestic and foreign standards and planning objectives issued by the government, according to the sample data distribution characteristics and experience at the same time, of which the indicators were divided into: safe, relatively safe, critically safe, unsafe and extremely unsafe. This was then used to determine the corresponding index level threshold (Table 2). The unit water body chemical oxygen demand (COD) load and ammonia $\left(\mathrm{NH}_{3}-\mathrm{N}\right)$ load were classified in accordance with "China's Surface Water Environmental Quality Standard" (GB3838-2002). The average slope of the Earth's surface and the average elevation were classified following the relevant classification criteria in the "Guizhou province geographical conditions census bulletin." Based on the data on Guizhou Province in the "Analysis of the Influence of Surface Fluctuation on Guizhou Public Finance Expenditure," we determined the classification criteria for the surface undulating index. Following expert opinion and sample data distribution characteristics, we set the grading standard of water consumption per unit area, the karst area specific gravity classification standard, the classification standard of cultivated land area proportion and 
the classification standard of proportion of construction land area. The remaining indicators were determined by referring to the above relevant literature.

Table 2. Water resources security indicator grading standards and thresholds.

\begin{tabular}{|c|c|c|c|c|c|c|}
\hline \multirow{2}{*}{ Specific Indicators } & \multicolumn{6}{|c|}{ Security Type } \\
\hline & & $\begin{array}{l}\text { Extremely } \\
\text { Unsafe }\end{array}$ & Unsafe & $\begin{array}{l}\text { Critically } \\
\text { Safe }\end{array}$ & $\begin{array}{l}\text { Relatively } \\
\text { Safe }\end{array}$ & Safe \\
\hline Water Resources Security Comprehensive Index & 0 & 0.2 & 0.4 & 0.6 & 0.8 & 1 \\
\hline Water resource background index & 0 & 0.2 & 0.4 & 0.6 & 0.8 & 1 \\
\hline Human activity intensity index & 0 & 0.2 & 0.4 & 0.6 & 0.8 & 1 \\
\hline Geological and geomorphological features index & 0 & 0.2 & 0.4 & 0.6 & 0.8 & 1 \\
\hline Precipitation $(\mathrm{mm})$ & 0 & 823 & 987 & 1097 & 1206 & 1371 \\
\hline Groundwater specific gravity (\%) & 50 & 40 & 30 & 20 & 10 & 0 \\
\hline Runoff coefficient & 0 & 0.2 & 0.4 & 0.6 & 0.8 & 1 \\
\hline River network density $\left(\mathrm{km} / \mathrm{km}^{2}\right)$ & 0 & 0.3 & 0.4 & 0.5 & 0.6 & 0.7 \\
\hline Water resources per capita $\left(\mathrm{p} / \mathrm{m}^{3}\right)$ & 0 & 1000 & 1700 & 2200 & 2700 & 3400 \\
\hline Surface water exploitation rate $(\%)$ & 50 & 40 & 30 & 20 & 10 & 0 \\
\hline Groundwater exploitation rate (\%) & 50 & 40 & 30 & 20 & 10 & 0 \\
\hline Population density $\left(\mathrm{p} / \mathrm{km}^{2}\right)$ & 500 & 400 & 300 & 200 & 100 & 0 \\
\hline $\begin{array}{l}\text { Water consumption of industrial output value } \\
\qquad\left(\mathrm{m}^{3} / 10,000 \text { yuan }\right)\end{array}$ & 1000 & 500 & 200 & 100 & 50 & 0 \\
\hline $\begin{array}{l}\text { Water consumption of agricultural output value } \\
\qquad\left(\mathrm{m}^{3} / 10,000 \text { yuan }\right)\end{array}$ & 10,000 & 5000 & 2000 & 1000 & 500 & 0 \\
\hline Domestic water consumption $\left(\mathrm{m}^{3} / \mathrm{p}\right)$ & 100 & 80 & 60 & 40 & 20 & 0 \\
\hline $\begin{array}{l}\text { Ecological water consumption per unit area } \\
\qquad\left(\mathrm{m}^{3} / \mathrm{km}^{2}\right)\end{array}$ & 0 & 100 & 200 & 500 & 1000 & 2000 \\
\hline Unit water body COD load (mg/L) & 40 & 30 & 20 & 15 & 10 & 0 \\
\hline Unit water body $\mathrm{NH}_{3}-\mathrm{N}$ load $(\mathrm{mg} / \mathrm{L})$ & 2 & 1.5 & 1 & 0.5 & 0.15 & 0 \\
\hline Average slope of land surface & 50 & 35 & 25 & 15 & 5 & 0 \\
\hline Surface undulation index & 1.5 & 1.4 & 1.3 & 1.2 & 1.1 & 1 \\
\hline Karst area proportion $(\%)$ & 100 & 80 & 60 & 40 & 20 & 0 \\
\hline Average altitude & 3000 & 2000 & 1500 & 1000 & 500 & 0 \\
\hline Vegetation coverage (\%) & 0 & 50 & 60 & 70 & 80 & 100 \\
\hline Proportion of cultivated land area (\%) & 50 & 40 & 30 & 20 & 10 & 0 \\
\hline Proportion of construction land area (\%) & 1 & 0.8 & 0.6 & 0.4 & 0.2 & 0 \\
\hline
\end{tabular}

(3) Multi-objective fuzzy membership function standardization method

Common methods for standardizing the attribute values of different dimensional indicators include proportional standardization, standard deviation standardization and dispersion standardization [31]. However, these methods are only adopted in the calculation of sample data, where the standardized values would be comparable within the range of the sample data. In addition, if a certain indicator in an area is relatively large, the normalized value of the indicator in other areas would approach 0 . In a sense, the indicator could not reflect differences with other areas. Therefore, this study adopted the multi-objective fuzzy membership function standardization method [3].

We formulated the indicator set as $w=\left\{w_{1}, w_{2}, \ldots, w_{j}\right\}$ and the comment set as $H=$ $\left\{h_{1}, h_{2}, h_{3}, h_{4}, h_{5}\right\}$. In combination with the WRS index standard shown in Table $2, h_{1}, h_{2}, h_{3}, h_{4}, h_{5}$ represent extremely unsafe, unsafe, critically safe, relatively safe and safe, respectively. The Water Resources Security Comprehensive Index (WRSCI) intervals corresponding to $h_{1}, h_{2}, h_{3}, h_{4}, h_{5}$ are $\left[k_{1}, k_{2}\right),\left[k_{2}, k_{3}\right),\left[k_{3}, k_{4}\right),\left[k_{4}, k_{5}\right),\left[k_{5}, k_{6}\right]$. Among them, $k_{1}=0, k_{2}=0.2, k_{3}=0.4, k_{4}=0.6, k_{5}=0.8$, $k_{6}=1$. For any indicator $j$, the standard values of the WRSCI thresholds $k_{1}, k_{2}, k_{3}, k_{4}, k_{5}, k_{6}$ are $u_{1}, u_{2}$, $u_{3}, u_{4}, u_{5}, u_{6}$ respectively.

For the positive indicators, the degree of membership was calculated by

$$
s_{\lambda i j}=\left\{\begin{array}{cc}
k_{1} & x_{\lambda i j}<u_{1} \\
\frac{k_{n+1}-k_{n}}{u_{n+1}-u_{n}} \times\left(x_{\lambda i j}-u_{n}\right)+k_{n} u_{n} \leq x_{\lambda i j} \leq u_{n+1}(1 \leq \mathrm{n} \leq 5) \\
k_{6} & x_{\lambda i j}>u_{6}
\end{array}\right.
$$


For the negative indicators, the degree of membership was calculated using

$$
s_{\lambda i j}=\left\{\begin{array}{cc}
k_{1} & x_{\lambda i j}>u_{1} \\
\frac{k_{n+1}-k_{n}}{u_{n+1}-u_{n}} \times\left(x_{\lambda i j}-u_{n}\right)+k_{n} u_{n+1} \leq x_{\lambda i j} \leq u_{n}(1 \leq \mathrm{n} \leq 5) \\
k_{6} & x_{\lambda i j}<u_{6}
\end{array}\right.
$$

In Equations (5) and (6), $s_{\lambda i j}$ is the membership or normalization value of the $j$-th index of region $i$ in year $\lambda$ and $x_{\lambda i j}$ is the actual value of the $j$-th index of region $i$ in year $\lambda$.

(4) Composite index

Based on the standardized value and comprehensive weight of each indicator, the weighted method was used to calculate the comprehensive index of each criterion layer and target layer, for example, the target layer's comprehensive index was estimated using:

$$
F_{\lambda i}=\sum_{k=1}^{m} \sum_{j=1}^{n}\left(s_{k}^{l} \times s_{j}^{k} \times s_{\lambda i j}\right)
$$

where $F_{\lambda i}$ is the comprehensive index of WRS of region $i$ in year $\lambda, s_{j}^{k}$ is the comprehensive weight of the indicator relative to the criterion layer, $s_{k}^{l}$ is the comprehensive weight of the criterion layer relative to the target layer, $m$ and $n$ represent the number of evaluation indexes in the criterion layer and the index layer, respectively.

The composite index of criteria layer can be estimated using:

$$
F_{\lambda k i}=\sum_{j=1}^{n}\left(s_{j}^{k} \times s_{\lambda i j}\right)
$$

where $F_{\lambda k i}$ is the WRS index of the $k$ criterion layer of region $i$ in year $\lambda, s_{j}^{k}$ is the comprehensive weight of the indicator relative to the criterion layer and $n$ represents the number of evaluation indicators in the indicator layer.

\section{Case Studies}

\subsection{Study Area}

Guizhou Province is located in the hinterlands of southwest China (Figure 2). It has six prefecture-level cities and three autonomous prefectures. The administrative area has a total area of 176.67 million $\mathrm{km}^{2}$. The territory is high in the west and low in the east. It inclines from the central to the east, north and south. The karst landform is widely developed. Landforms such as mountains, hills and basins are widely distributed and it is known as "eight mountains, one water and one field."

Guizhou Province has a subtropical humid monsoon climate, with clear seasons, abundant rainfall, rain and heat during the same period. The average temperature in the coldest month (January) is generally $3 \sim 6{ }^{\circ} \mathrm{C}$ and the average temperature in the hottest month (July) is generally $22 \sim 25{ }^{\circ} \mathrm{C}$. The annual average precipitation is $1095 \mathrm{~mm}$ and the occurrence of precipitation is mostly concentrated from June to September. Guizhou Province is mostly karst landform and its surface water storage capacity is weak. In addition, the average altitude is high and the average slope is steep. It is difficult to develop and utilize water resources, which makes water supply and water use difficult.

\subsection{Data Source}

The research data were mainly extracted from "the water resources bulletin of Guizhou province (2001-2015)," the "Guizhou statistical yearbook (2001-2015)," "the bulletin of environmental conditions" in various cities and states of Guizhou Province (2001-2015) and the "Guizhou province geographical conditions census bulletin." The surface undulation index is derived from "an analysis 
of the impact of land surface fluctuation on Guizhou's fiscal public expenditure". The vegetation coverage, proportion of cultivated land area and the proportion of construction land area were derived from the Landsat TM5 image of Guizhou Province from 2010. Since it is difficult to obtain the data of these three indicators and their annual variations are not significant, we set them as constant for 2010.

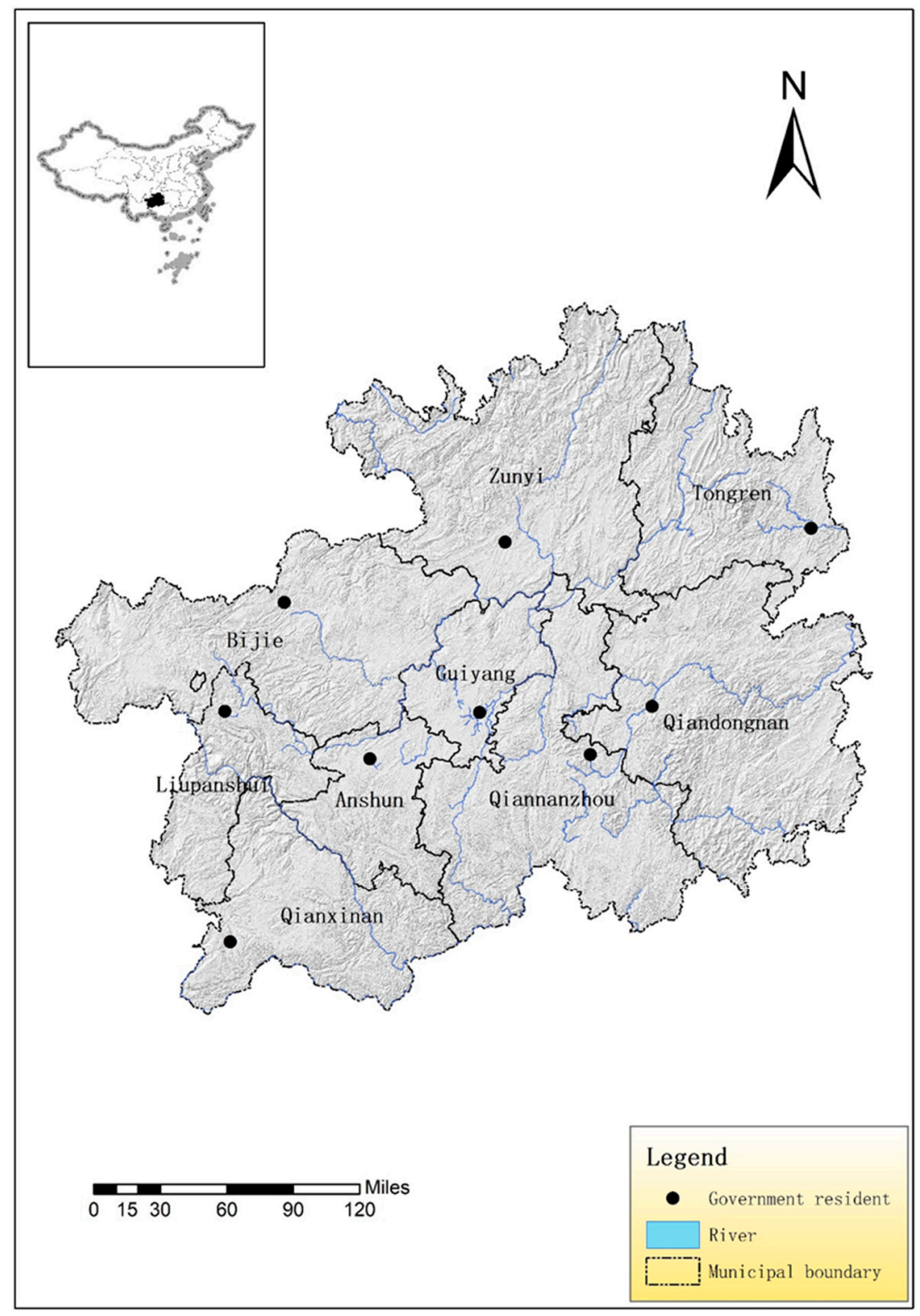

Figure 2. Location and range map of the study area.

\subsection{Results and Discussion}

\subsubsection{Characteristics of WRS in Guizhou Province}

Figure 3 displays the changes in the water resources security index of Guizhou Province in the study period (2001-2015). The WRSCI (Water Resources Security Comprehensive Index) gradually increased from 0.63 in 2001 to 0.67 in 2015 . Whilst the WRSCI in most years was the relatively safe type (ranged between 0.6 and 0.8 ), it hit a critically safe type level of 0.59 in 2011. Among the water resources security indices, the GGFI (Geological and Geomorphological Features Index) remained constant over the study period. In contrast, the fluctuations of the WRBCI (Water Resources Background Conditions 
Index) were primarily influenced by natural conditions. The HAII (Human Activities Intensity Index), driven by social and economic developments, gradually developed into relatively safe type. Despite the fluctuation of WRBCI, the gradual improvement of HAII contributed to the improvement of WRSCI in the study period.

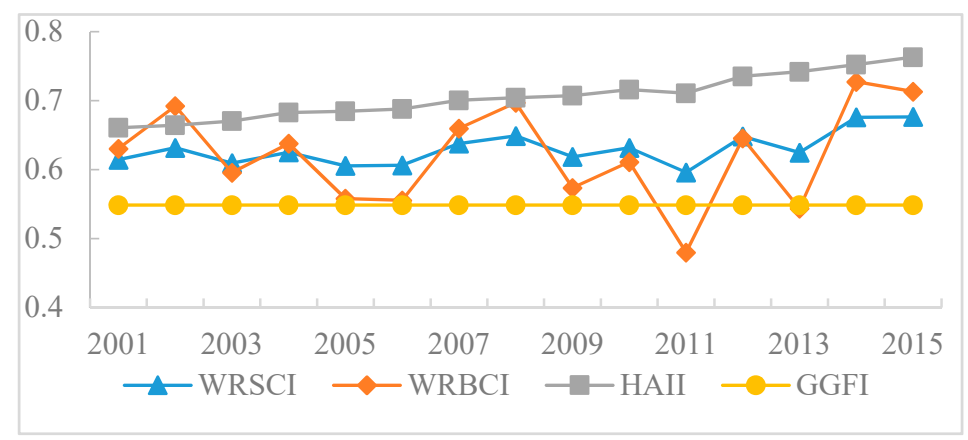

Figure 3. Changes in the Water Resources Security Index of Guizhou Province in 2001-2015.

Figure 4 shows the WRBC (Water Resources Background Conditions) indicators of Guizhou Province. From 2001 to 2015, the WRBCI ranged between 0.4 and 0.8 , suggesting that the water resources conditions of the province were generally of the critically safe and relatively safe type. Among the indicators, the normalized value of $X_{1}$ fluctuated significantly (between 0.19 and 0.88 ) but stayed between 0.6 and 0.8 (i.e., relatively safe type) in most years. The normalized values of $X_{2}$ ranged between 0.4 and 0.6 , except for several years that hit levels above 0.6 , the critically safe type. The standardized values of $X_{3}$ and $X_{4}$ showed little change and were of the critically safe and relatively safe type, respectively. The trend of the standardized value of $X_{5}$ (similar to that of $X_{1}$ ) was higher than 0.6 in most years and could be categorized as a relatively safe or safe type. Specifically, the WRBC was primarily affected by changes in $X_{1}$, that caused WRBCI fluctuations to fluctuate to a greater degree.

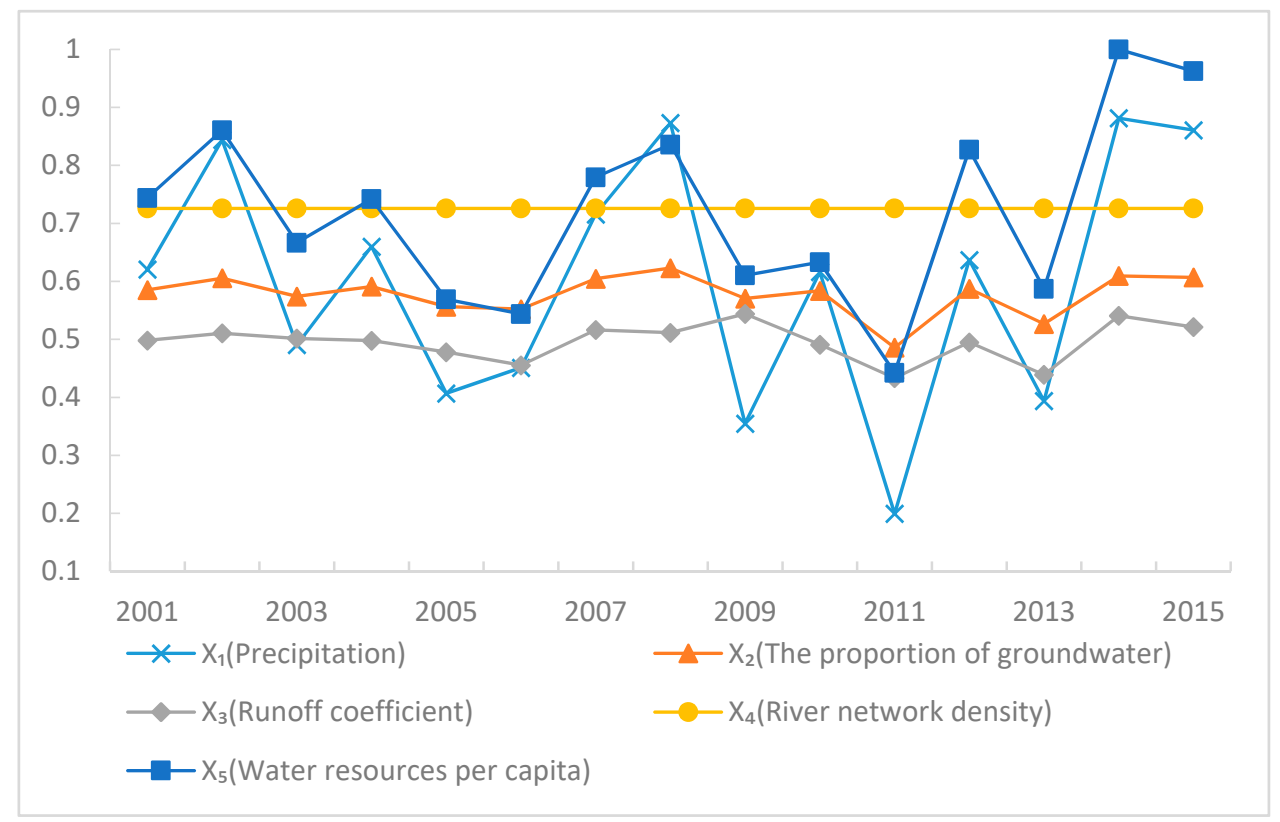

Figure 4. Changes in WRBC (Water Resources Background Conditions) indicators of Guizhou Province in 2001-2015. 
The changes in the indicators of HAI (Human Activity Intensity) of Guizhou Province are shown in Figure 5. Improvement in the human awareness of WRS as well as social and economic behaviour caused the HAII to rise from 0.66 to 0.76 in 2001-2015. HAII values were of the relatively safe type and were trending upward. Among them, the standardized values of $X_{6}$ were all above 0.6 (i.e., relatively safe and safe types). The standardized values of $X_{7}$ and $X_{13}$ are ranged between 0.8 and 1 and were of a Safe type. The standardized value of $X_{8}$ trended slightly upwards and varied between 0.55 and 0.65 , thus belonging to the critically safe and relatively safe types. The standardized values of $X_{9}$ and $X_{10}$ increased most significantly, increasing from 0.22 (unsafe type) and 0.48 (critically safe type) in 2001 to 0.77 (relatively safe type) and 0.87 (safe type) in 2015, respectively. The standardized value of $X_{11}$ was affected by the improvement in residents' quality of life and the increase of water consumption and hence reduced from the relatively safe type before 2011 to the critically safe type. The standardized value of $X_{12}$ increased from 0.41 in 2001 to 0.54 in 2015 and maintained its status as a critically safe type. Whilst the standardized values of $X_{13}$ were above 0.6 , they were trending downwards due to pollutant discharge. Specifically, the main impact of $X_{9}$ and $X_{10}$ reduction year by year was a year by year increase in HAII.

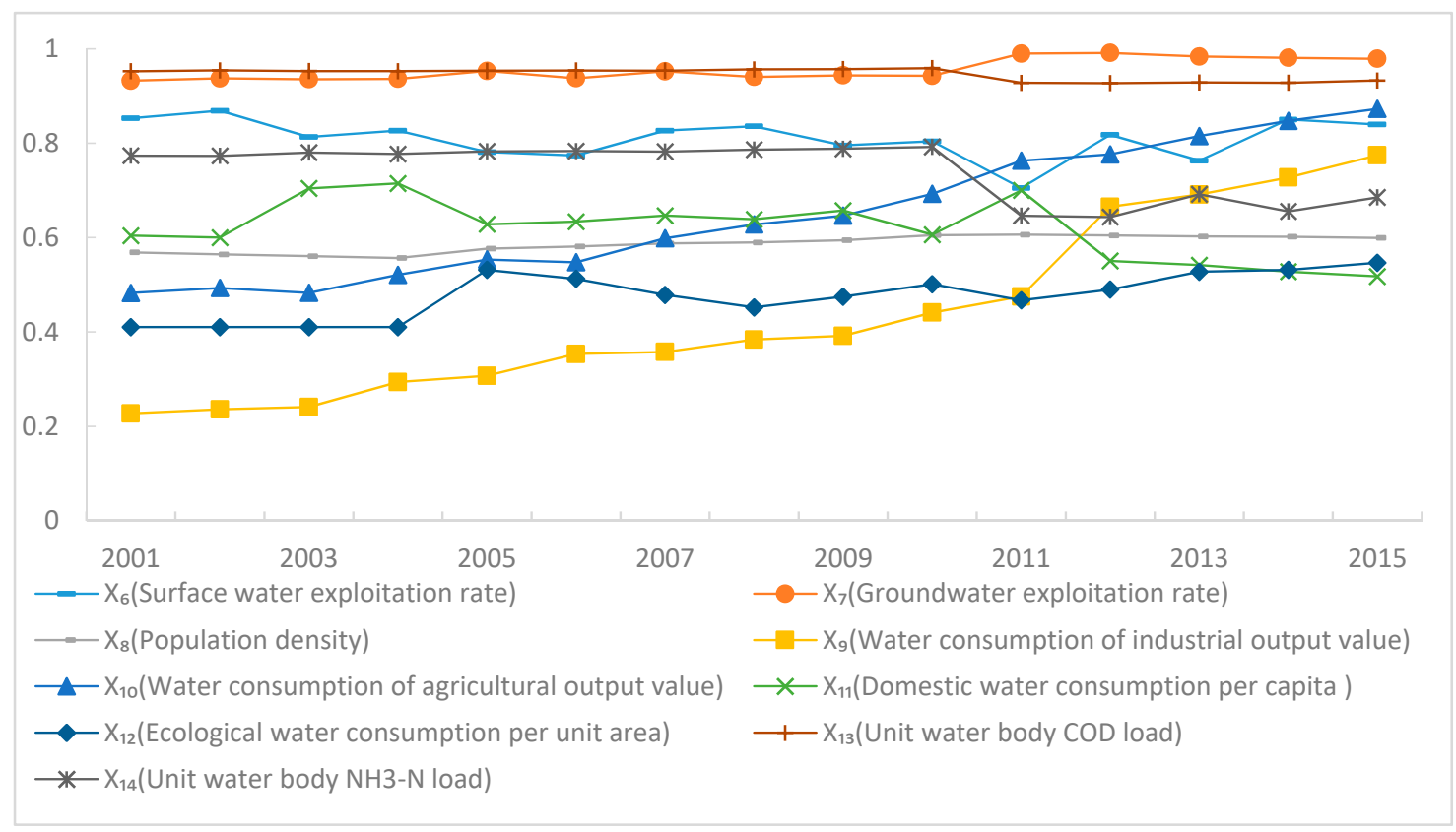

Figure 5. Changes in HAI (Human Activity Intensity) indicators of Guizhou Province in 2001-2015.

\subsubsection{Spatiotemporal Patterns of Water Resources Security in Guizhou Province}

Figure 6 illustrates the spatiotemporal patterns of the WRSCI (Water Resources Security Comprehensive Index) in various cities and states in Guizhou Province for 2001-2015. In the study period, all cities and states in Guizhou Province were experiencing critically safe and relatively safe types, which improved gradually from the northwest to the southeast. From 2001 to 2015, the multi-year average of the WRSCI for Guiyang, Anshun, Bijie and Liupanshui was between 0.4 and 0.6 (critically safe type), accounting for $44 \%$ of Guizhou Province and that of the remaining five cities and states it was between 0.6 and 0.8 (relatively safe type), accounting for $56 \%$ of Guizhou Province. 

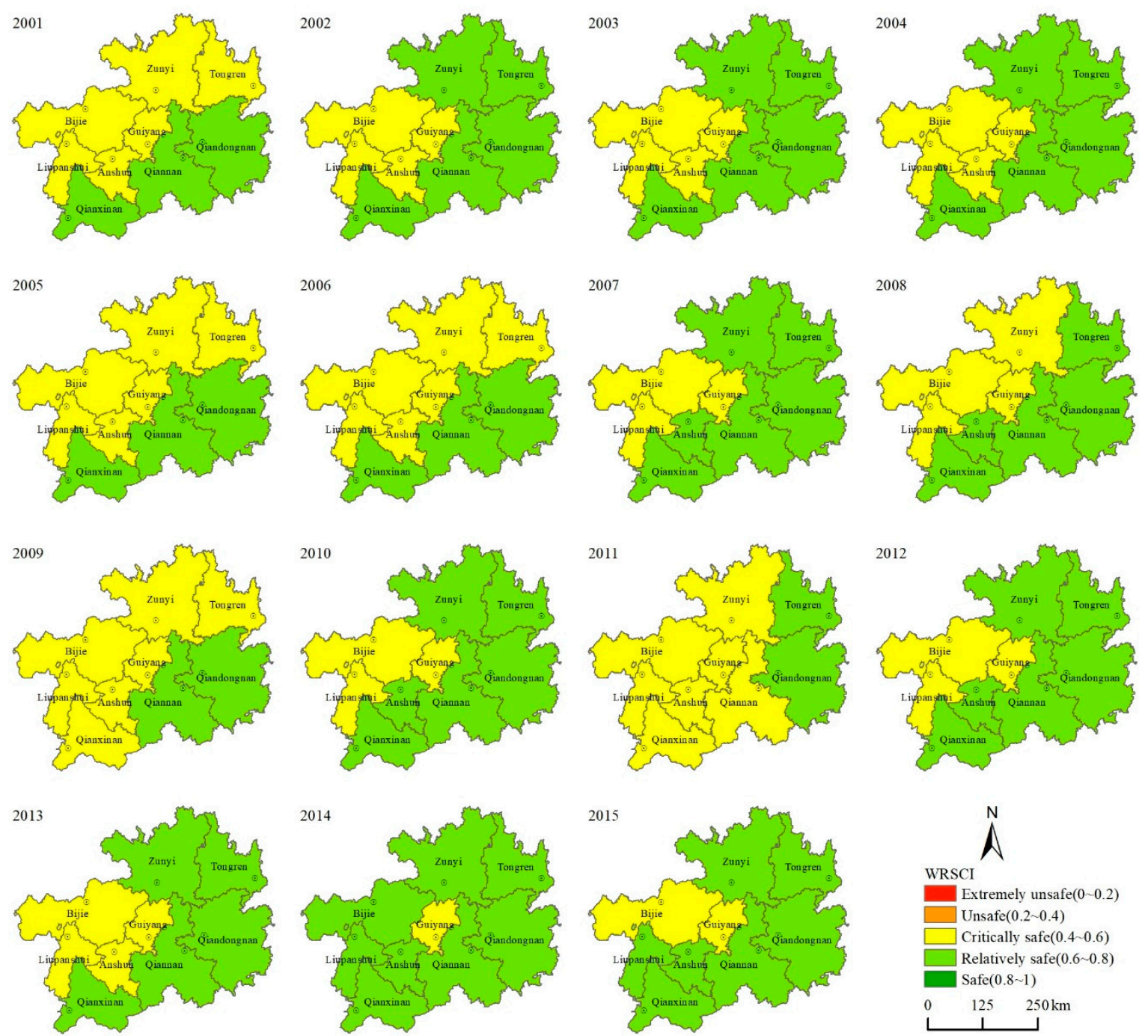

Figure 6. Spatiotemporal patterns of the WRSCI (Water Resources Security Comprehensive Index) in various cities and states in Guizhou Province in 2001-2015.

The spatiotemporal patterns of the WRBCI (Water Resources Background Conditions Index) in various cities and states in Guizhou Province for 2001-2015 are displayed in Figure 7. In 2001-2015, most of the cities and states in Guizhou Province belonged to the critically safe types and the relatively safe types (a few were unsafe types, some were safe types). The WRBCI improved from the northwest to the southeast of Guizhou Province. The outcomes of the multi-year average of the WRBCI showed that, Guiyang, Zunyi, Anshun, Bijie and Liupanshui ranged between 0.4 and 0.6 (critically safe type), accounting for $56 \%$ of Guizhou Province. Among these cities, the average value of Bijie was the lowest (at 0.46), mainly because of the low precipitation, high proportion of groundwater and the low runoff coefficient. The WRBCI values of the remaining cities and states ranged between 0.6 and 0.8 , accounting for $44 \%$ of Guizhou Province, which is a relatively safe type. Among them, the average WRBCI value of Qiandongnan was the highest (at 0.74 ) because of the high river network density, high runoff coefficient and large per capita water resources. 

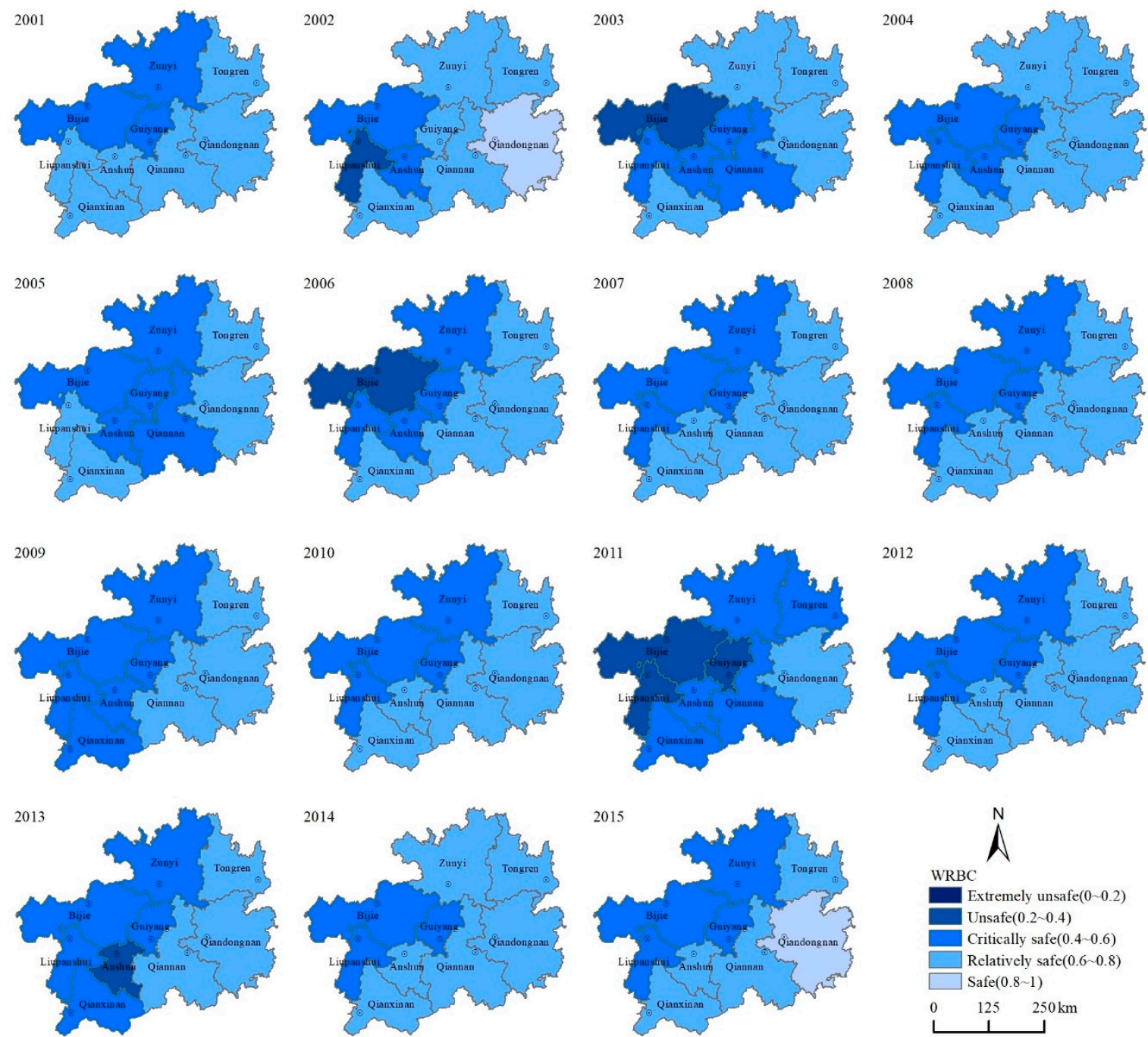

Figure 7. Spatiotemporal patterns of the WRBCI (Water Resources Background Conditions Index) in various cities and states in Guizhou Province in 2001-2015.

The spatiotemporal patterns of the HAII (Human Activity Intensity Index) in various cities and states in Guizhou Province for 2001-2015 are demonstrated in Figure 8. From 2001 to 2015, all cities and states in Guizhou Province were classified as critically safe and relatively safe types. Spatially, the critically safe types were mainly concentrated in Guiyang, Tongren and Qianxinan. Based on the multi-year average of HAII in 2001-2015, only Guiyang demonstrated a HAII ranges of somewhere between 0.4 and 0.6 (i.e., critically safe type) with an average annual value of 0.57 . Its population density was large, the per capita living water consumption was high, the surface and groundwater exploitation rate was high and the water body was seriously polluted. The HAII value of the remaining cities and states ranged between 0.6 and 0.8 (relatively safe type), accounting for $89 \%$ of Guizhou Province.

Figure 9 presents the spatial distribution of the GGFI (Geological and Geomorphological Features Index) in various cities and states in Guizhou Province. All the cities and states in Guizhou belong to the relatively safe and critically safe types, which gradually improve from the west to the east of the province. Tongren and Qiandongnan have GGFI values of 0.61 and 0.69 , respectively and both are relatively safe types. In Qiandongnan, the vegetation coverage is high, while the proportions of cultivated land and karst area are small. The GGFI values of the remaining cities and states are between 0.4 and 0.6 (critically safe type), accounting for 78\% of Guizhou Province. Among them, 
Bijie has the smallest GGFI at 0.47 , characterized by a large karst area ratio, a high average altitude and low vegetation coverage.
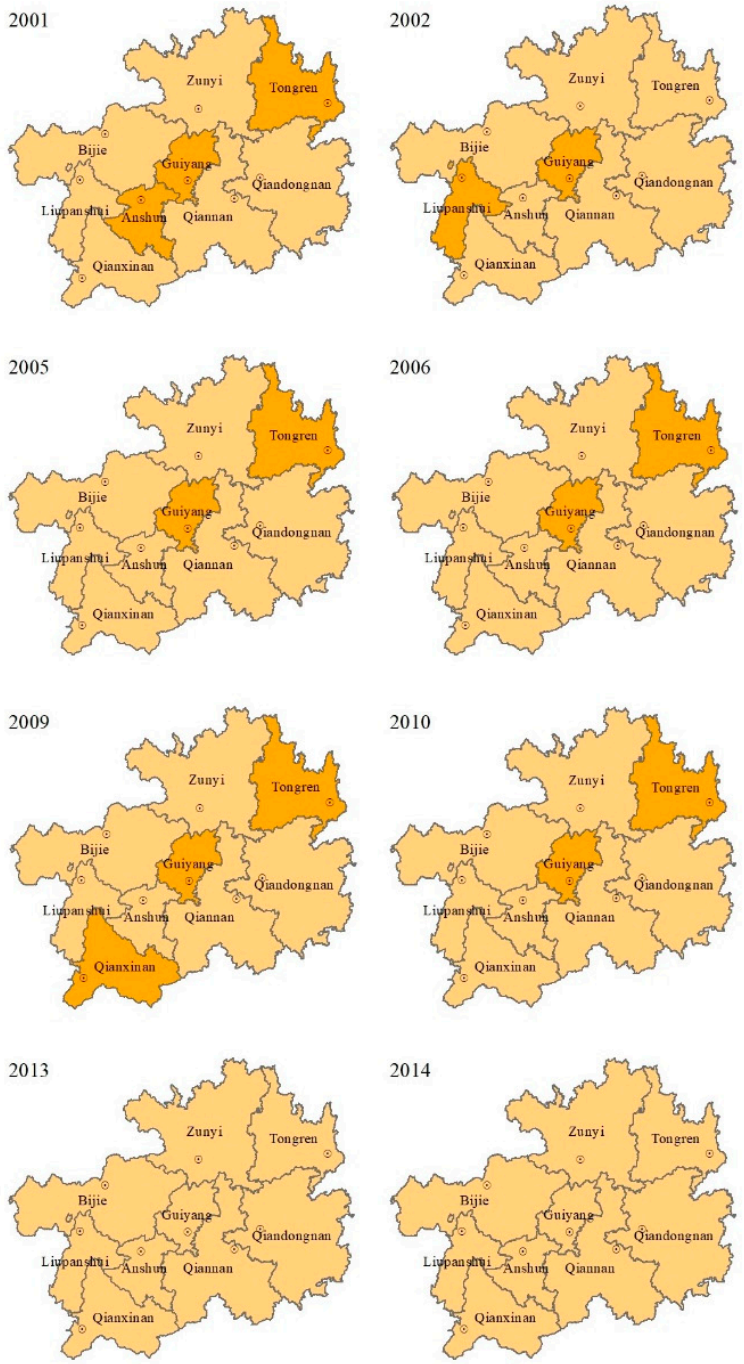

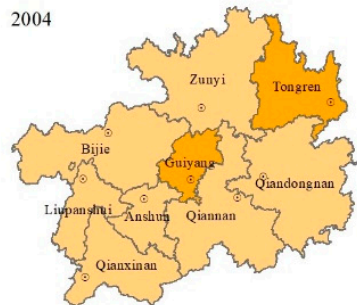

2007
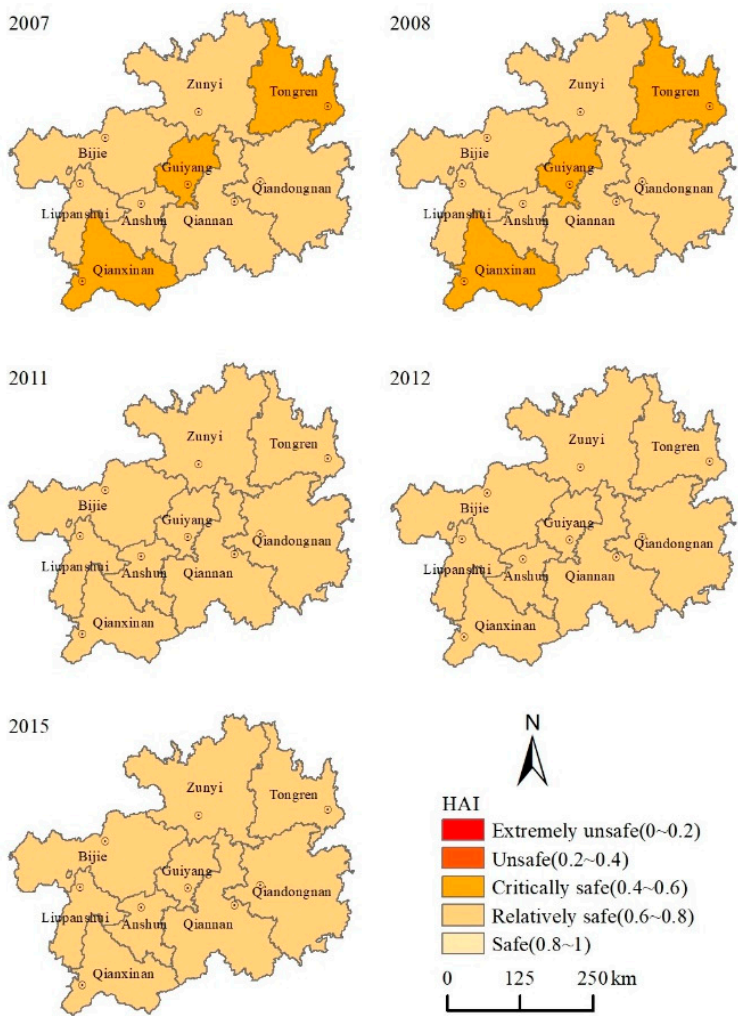

Figure 8. Spatiotemporal patterns of the HAII (Human Activity Intensity Index) in various cities and states in Guizhou Province in 2001-2015.

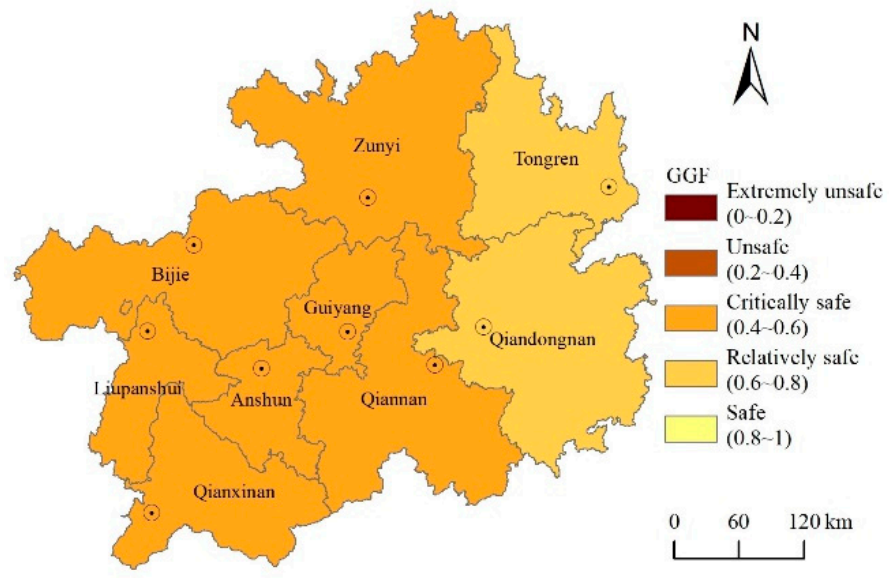

Figure 9. Spatial distribution of the GGFI (Geological and Geomorphological Features Index) in various cities and states in Guizhou Province in 2010. 


\subsubsection{Factors Affecting Water Resources Security}

A correlation analysis is typically used to analyse the relationship between two sets of variables $[32,33]$. Here, we show the correlation results between the WRS status and various indicators in Tables 3 and 4 . They include the correlation analysis between the WRSCI of each city in Guizhou and the change indicators in the indicator layer, the WRSCI average value of each city in Guizhou and the fixed indicators in the indicator layer. Table 3 shows that most of the WRSCI values in Guizhou Province and its cities have different degrees of positive correlation with $X_{1}, X_{3}$ and $X_{5}$ at the 0.01 and 0.05 levels; different degrees of negative correlation with $X_{2}, X_{6}, X_{7}, X_{9}$ and $X_{10}$ at the 0.01 and 0.05 levels; and different degrees of positive or negative correlation with $X_{8}, X_{12}, X_{13}$ and $X_{14}$ but there are not significant. Some outliers, like $X_{13}$, are negative indicators but the correlation coefficient between $X_{13}$ and the WRSCI of each city in Guizhou Province is positive and positively correlated; this is because WRSCI is comprehensive and affected by various indicators, so the impacts of other indicators on WRSCI offset or even exceed the impact of $X_{13}$ on WRSCI, which makes the result appear contradictory.

Table 3. Pearson correlation coefficient between the WRSCI and change indicators in various cities and states in Guizhou Province.

\begin{tabular}{|c|c|c|c|c|c|c|c|c|c|c|}
\hline Index & $\begin{array}{l}\text { Guizhou } \\
\text { Province }\end{array}$ & Guiyang & Zunyi & Anshun & Bijie & Tongren & Qianxinan & Qiandongnan & Qiannan & Liupanshui \\
\hline$X_{1}$ & $0.825^{* *}$ & $0.799^{* * *}$ & $0.670^{* *}$ & $0.827^{* *}$ & $0.690^{* *}$ & $0.532^{*}$ & $0.557^{*}$ & $0.672^{* *}$ & $0.840^{* *}$ & $0.677^{* *}$ \\
\hline$X_{2}$ & $-0.709^{* *}$ & $-0.515^{*}$ & $-0.571^{*}$ & $-0.844^{* *}$ & $-0.718^{* *}$ & -0.016 & -0.160 & -0.151 & $-0.693^{* *}$ & $-0.912^{* *}$ \\
\hline$X_{3}$ & $0.614^{*}$ & 0.332 & $0.758^{* *}$ & $0.706^{* *}$ & $0.549^{*}$ & 0.139 & -0.018 & 0.269 & $0.783^{* *}$ & $0.716^{* *}$ \\
\hline$X_{5}$ & $0.917^{* *}$ & 0.265 & $0.919^{* * *}$ & $0.928^{* *}$ & $0.887^{* *}$ & $0.708^{* *}$ & 0.425 & $0.774^{* *}$ & $0.835^{* *}$ & 0.504 \\
\hline$X_{6}$ & $-0.619^{*}$ & $-0.546^{*}$ & $-0.754^{* *}$ & $-0.681^{* *}$ & $-0.554^{*}$ & -0.183 & -0.402 & -0.267 & $-0.839^{* *}$ & -0.273 \\
\hline$X_{7}$ & -0.360 & $-0.629^{*}$ & -0.314 & -0.412 & -0.065 & $0.706^{* *}$ & $0.738^{* *}$ & $-0.614^{*}$ & -0.241 & 0.390 \\
\hline$X_{9}$ & $-0.554^{*}$ & $-0.709^{* *}$ & -0.290 & -0.264 & $-0.615^{*}$ & $-0.604^{*}$ & 0.051 & $-0.741^{* *}$ & $-0.522^{*}$ & $-0.549^{*}$ \\
\hline$X_{10}$ & $-0.567^{*}$ & $-0.615^{*}$ & -0.451 & $-0.582^{*}$ & $-0.785^{* *}$ & -0.371 & -0.090 & $-0.811^{* *}$ & $-0.542^{*}$ & -0.384 \\
\hline$X_{11}$ & $0.698^{* *}$ & 0.464 & 0.147 & 0.400 & $0.737^{* *}$ & 0.358 & 0.066 & $0.524^{*}$ & 0.490 & 0.242 \\
\hline$X_{12}$ & 0.365 & 0.232 & 0.510 & 0.265 & 0.474 & -0.011 & 0.103 & 0.120 & 0.264 & 0.082 \\
\hline$X_{13}$ & 0.363 & 0.332 & 0.356 & 0.151 & -0.027 & $0.586^{*}$ & 0.506 & $0.590^{*}$ & -0.397 & -0.140 \\
\hline$X_{14}$ & 0.380 & $0.688^{* *}$ & 0.186 & 0.167 & -0.029 & $0.640^{*}$ & -0.101 & $0.624^{*}$ & 0.221 & 0.023 \\
\hline
\end{tabular}

** Significantly correlated at the 0.01 level (both sides). * Significantly correlated at the 0.05 level (both sides).

Table 4. Pearson correlation coefficient between the WRSCI average value and constant indicators of each city and state in Guizhou Province.

\begin{tabular}{ccccccccc}
\hline Index & $X_{4}$ & $X_{15}$ & $X_{16}$ & $X_{17}$ & $X_{18}$ & $X_{19}$ & $X_{20}$ & $X_{21}$ \\
\hline $\begin{array}{c}\text { Composite index } \\
\text { average }\end{array}$ & $0.760^{*}$ & $-0.808^{* *}$ & $0.668^{*}$ & $-0.770^{* *}$ & $-0.713^{*}$ & $0.832^{* *}$ & $-0.764^{*}$ & -0.592 \\
\hline
\end{tabular}

** Significantly correlated at the 0.01 level (both sides). * Significantly correlated at the 0.05 level (both sides).

It can be seen from Table 4 that the comprehensive index of WRS is negatively correlated with $X_{15}$ and $X_{17}$ at the 0.01 level; negatively correlated with $X_{18}$ and $X_{20}$ at the 0.05 level; and positively correlated with $X_{4}$ and $X_{16}$ at the 0.05 level; and negatively correlated with $X_{21}$ (but not significantly). The main reason for these results is that the geological and geomorphological features are different between different cities and states, which are affected by geological and geomorphological features; $X_{4}$ and $X_{20}$ are also different.

\section{Conclusions}

Based on the concepts of the "man-land-water" model, we constructed a comprehensive evaluation index system and evaluation standard of water security for Guizhou. The analytic hierarchy process (AHP) and entropy weight method were used to determine the subjective and objective weights. We adopted the Lagrange multipliers to obtain the comprehensive weight. Based on the multi-objective fuzzy membership function, we evaluated the spatial and temporal characteristics of water resource security in Guizhou Province from 2001 to 2015. The main conclusions are as follows: 
(1) Water resources background conditions in Guizhou Province were of the critically safe type in most years. The human activity intensity was of the relatively safe type and demonstrated an upward trend over the study period, gradually transforming to the safe type. The geological and geomorphological features of the majority of the states were of the critically safe type and remained constant. The water resource security comprehensive index ranged between 0.6 and 0.8 in most years, which was generally of the relatively safe type. Despite the substantial fluctuations in precipitation and, thus, per capita water resources, the significant decline of the water consumption of the industrial output value $\left(\mathrm{m}^{3} / 10,000\right.$ yuan) and the water consumption of the agricultural output value $\left(\mathrm{m}^{3} / 10,000\right.$ yuan) enabled the overall development of water resources towards the direction of the safe type.

(2) The water resource background conditions were poor in the northwest but good in the southeast of Guizhou Province. The geological and geomorphological features of the east are excellent but inferior to the west of the province. The human activity intensity was affected by the urban economy and water resource utilization efficiency and the areas with poor water resources background conditions were mainly Guiyang, Tongren and Qianxinan. The spatial dislocation of the three factors finally led to a certain degree of difference in the Water Resource Security Comprehensive Index of Guizhou province on the space-time scale. The overall water resources background conditions were low in the west and high in the east of the province and generally improved over time (except for Guiyang, which remained as critically safe type). Despite the spatiotemporal variations in the water resource security criteria layer indices in each city of Guizhou Province, the characteristics of regional consistency between water resource background conditions and the geological and geomorphic features were significant (probably related to the innate influences among them). Overall, 56 percent of the city and state Water Resource Background Condition Indexes were of the critically safe type; 89 percent of the city and state Human Activity Intensity Indexes were of the relatively safe type; 78 percent of city Geological and Geomorphological Features Indexes were of the critically safe type; and 56 percent of city and state Water Resources Security Comprehensive Indexes were of the relatively safe type.

(3) The Water Resources Security Comprehensive Index in various cities and states in Guizhou Province were positively correlated with these factors: precipitation, runoff coefficient, water resources per capita and river network density at different levels (between 0.01 and 0.05), groundwater specific gravity, surface water exploitation rate, groundwater exploitation rate, water consumption of the industrial output value $\left(\mathrm{m}^{3} / 10,000\right.$ yuan), water consumption of the agricultural output value $\left(\mathrm{m}^{3} / 10,000\right.$ yuan), average slope of the land surface, karst area proportion and average altitude. In contrast, the proportion of cultivated land area showed varying degrees of negative correlation at the 0.01 and 0.05 levels. To improve the water resources security, future efforts should focus on strengthening the ecological environment governance, readjusting industrial structure, improving water resources utilization technology, having better water resources management and establishing sound management measures and security system related institutions.

From the "man-land-water" perspective, this paper developed an evaluation model for water resource security in Guizhou Province and karst regions. A comprehensive evaluation on the spatiotemporal patterns of water resource security of Guizhou Province was performed. Nonetheless, the current study has two shortfalls: (i) no in-depth analysis of the influencing mechanisms of geological and geomorphological features on water resources security; and (ii) no detailed analysis of the changing mechanism of the water resource security pattern in each city of Guizhou Province. An upcoming study on water resources security will be conducted to address these limitations.

Author Contributions: The study was designed by Q.-W.Z. and W.-C.S. The data from yearbooks and professional websites were retrieved by Q.-W.Z. and Z.-Q.Z. Q.-W.Z. wrote the manuscript. F.-T.Z. provided important ideas and suggestions. 
Funding: This research was funded by the National Science and Technology project of the "13th Five-Year Plan" (2016YFC0400708, 2016YFC0502601-04), the Guizhou Province Key Scientific and Technological Project (QKH-JZ-2015-2001), the Chongqing Normal University Graduate Research and Innovation Project (YKC18034).

Acknowledgments: The authors are grateful to the editors and three anonymous reviewers for their constructive comments. And we thank Xin-Yuan LIANG for helping me a lot in graph editing and Qiong-Yao LI for modifying grammar problems in language.

Conflicts of Interest: The authors declare no conflict of interest.

\section{References}

1. Bao, C.; Fang, C.L. Water resources flows related to urbanization in China: Challenges and perspectives for water management and urban development. Water Res. Manag. 2012, 26, 531-552. [CrossRef]

2. Shao, D.G.; Yang, F.S.; Xiao, C.; Tan, X.Z. Evaluation of water security: An integrated approach applied in Wuhan urban agglomeration, China. Water Sci. Technol. 2012, 66, 79-87. [CrossRef]

3. Evaluation of water resources security pattern of Beijing-Tianjin-Hebei urban agglomeration based on human-water relationship. Acta Ecol. Sinica 2018, 38, 4180-4190.

4. Zhou, Z.Y.; Zhang, X.J.; Dong, W.Y. Fuzzy comprehensive evaluation for safety guarantee system of reclaimed. Procedia Environ. Sci. 2013, 18, 227-235. [CrossRef]

5. Moglia, M.; Neumann, L.E.; Alexander, K.S.; Nguyen, M.N.; Sharma, A.K.; Cook, S.; Trung, N.H.; Tuan, D.D.A. Application of the water needs index: Can Tho city, Mekong delta, Vietnam. J. Hydrol. 2012, 468-469, 203-212. [CrossRef]

6. Bai, Y.; Wang, P.; Li, C.; Xie, J.; Wang, Y. A multi-scale relevance vector regression approach for daily urban water demand forecasting. J. Hydrol. 2014, 517, 236-245. [CrossRef]

7. Raso, L.; Schwanenberg, D.; Giesen, N.D.; van Overloop, P.J. Short-term optimal operation of water systems using ensemble forecasts. Adv. Water Res. 2014, 71, 200-208. [CrossRef]

8. Karen, B. Water security: Research challenges and opportunities. Science 2012, 337, 914-915.

9. Chang, M.Q.; Liu, J.P. Basic concepts and research progress of water resources security. Chin. J. Saf. Sci. 2008, $18,12-21$.

10. Bhesh, R.T.; Hiroshi, I.; Vishnu Prasad, P.; Bahandari, T.M. Evaluation of water security in Kathmandu valley before and after water transfer from another basin. Water 2018, 10, 1-12.

11. Dai, W.; Zhai, H.X.; Tong, S.M. Study on water resources security evaluation index system. Water Sav. Irrig. 2012, 3, 40-47.

12. Guanghua, D.; Juqin, S.; Yizhen, J.; Fuhua, S. Comprehensive evaluation of water resource security: Case study from Luoyang city, China. Water 2018, 10, 1-19.

13. Zhang, F.T.; Wang, L.C.; Su, W.C.; YANG, Q.Q. Study on the "dualistic" water resources security evaluation of surface Karst zone based on entropy weight set. J. Hydroelectr. Eng. 2012, 31, 70-77.

14. Jia, X.; Li, C.; Cai, Y.; Wang, X.; Sun, L. An improved method for integrated water security assessment in the Yellow river basin, China. Stoch. Environ. Res. Risk Assess. 2015, 29, 1-15. [CrossRef]

15. Zhao, Z.; Liu, J.G.; Savenije, H.H.G. A simple approach to assess water scarcity integrating water quantity and quality. Ecol. Indic. 2013, 34, 441-449.

16. Liu, M.; Wei, J.H.; Wang, G.Q.; Wang, F. Water resources stress assessment and risk early warning a case of Hebei province China. Ecol. Indic. 2017, 358-368. [CrossRef]

17. Sullivan, C.A.; Meigh, J.R.; Giacomello, A.M. The Water Poverty Index: Development and Application at the Community Scale//Natural Resources Forum; Blackwell Publishing Ltd.: Hobokrn, NJ, USA, 2003; pp. $189-199$.

18. Sullivan, C. Calculating a water poverty index. World Dev. 2002, 30, 1195-1210. [CrossRef]

19. Li, G.; Jin, C.L. Fuzzy comprehensive evaluation for carrying capacity of regional water resources. Water Res. Manag. 2009, 23, 2505-2513.

20. Zhang, X.; Zhao, X.; Zhang, M.; Wu, Q.-Y. Safety evaluation of an artificial groundwater recharge system for reclaimed water reuse based on bioassays. Desalination 2011, 281, 185-189. [CrossRef]

21. Faghihi, F.; Ramezani, E.; Yousefpour, F.; Mirvakili, S.M. Level-1 probability safety assessment of the Iranian heavy water reactor using SAPHIRE software. Reliab. Eng. Syst. Saf. 2008, 93, 1377-1409. [CrossRef]

22. Chen, J.F.; Lu, X.; Wang, H.M.; Jin, Q. Research on urban water security early-warning based on support vector machines. Adv. Inf. Sci. Serv. Sci. 2012, 4, 191-199. 
23. Williamson, A. Feasibility study of a water safety data collection for beaches. J. Sci. Med. Sport 2006, 9, 243-248. [CrossRef]

24. Wu, K.Y.; Jin, J.L. A projection pursuit evaluation model for regional water resources based on variable weight and information entropy. J. Yangtze River Res. Environ. 2011, 20, 1085-1090.

25. Song, P.Z.; Wang, J.; Liu, W.; Yu, J.; Zhang, B. Water resources security evaluation model based on PSO optimized logistic curve. J. Nat Res. 2016, 31, 886-893.

26. Gong, S.Y.; Guan, H.; Chen, P.Y. Preliminary analysis of water resources security in Henan province. J. Henan Uni. (Nat.) 2005, 35, 46-51.

27. Zhang, F.T.; Wang, L.C.; Su, W.C. Water safety evaluation of karst area based on DPSIRM conceptual framework model. China Environ. Sci. 2015, 35, 3511-3520.

28. Yang, Z.H.; Zhou, Q.W.; Guo, Y.; Su, W.C.; Zhang, F.T. Dynamic evaluation of water resources security in Karst areas based on SPA-MC model-A case study of Guiyang city. China Environ. Sci. 2017, 37, 1589-1600.

29. Wang, W.G.; He, M.X.; Pan, K.; Zhu, Q.L.; Zhou, Y.; Fan, Y.; Hu, Q.C. Spatial and temporal analysis of water resources ecological footprint and ecological carrying capacity in Sichuan province. J. Nat. Res. 2011, $26,1555-1565$.

30. Saaty, T.L. A scaling method for priorities in hierarchical structures. J. Math. Psychol. 2000, 15, $234-281$. [CrossRef]

31. Pollesch, N.L.; Dale, V.H. Normalization in sustainability assessment: Methods and implications. Ecol. Econ. 2016, 130, 195-208. [CrossRef]

32. Geng, Z.F.; Zhang, Y.B.; Han, T.H.; Xing, X.N. Correlation analysis of urbanization level and water resources utilization in Aksu region. J. Tarim Uni. 2013, 25, 105-109.

33. Wang, X.Y.; Halik, W.H.F.; Musa, A.S.G.L.; Wang, Y.F.; Wang, F. Coordinated development of population-eco-water resources in Arid areas and their correlation Analysis-A case study of Urumqi county. Water Irrig. 2018, 101-105, 110.

(C) 2019 by the authors. Licensee MDPI, Basel, Switzerland. This article is an open access article distributed under the terms and conditions of the Creative Commons Attribution (CC BY) license (http:// creativecommons.org/licenses/by/4.0/). 